\title{
Dopamine and the biology of creativity: lessons from Parkinson's disease
}

\author{
Eugénie Lhommée ${ }^{1,2,3}$ *, Alina Batir ${ }^{1,2,3}$, Jean-Louis Quesada4, Claire Ardouin ${ }^{1,2,3}$, Valérie Fraix ${ }^{1,2,3}$, \\ Eric Seigneuret ${ }^{1,2,5}$, Stéphan Chabardès ${ }^{1,2,5}$, Alim-Louis Benabid ${ }^{5 t}$, Pierre Pollak ${ }^{1,2,3}$ and Paul Krack ${ }^{1,2,3}$ \\ ${ }^{1}$ U836, INSERM, Grenoble, France \\ ${ }_{2}^{2}$ University of Grenoble Alpes, GIN, Grenoble, France \\ ${ }^{3}$ Movement Disorder Unit, CHU de Grenoble, Grenoble, France \\ ${ }^{4}$ Centre d'Investigation Clinique, CHU de Grenoble, Université Joseph Fourier, Grenoble, France \\ ${ }^{5}$ Department of Neurosurgery, $\mathrm{CHU}$ de Grenoble, Grenoble, France
}

\section{Edited by:}

Jaime Kulisevsky, Sant Pau Hospital, Spain

\section{Reviewed by:}

Francesca Morgante, University of Messina, Italy

Ubaldo Bonuccelli, University of Pisa, Italy

\section{${ }^{*}$ Correspondence:}

Eugénie Lhommée, Movement Disorder Unit, Department of

Psychiatry and Neurology, CHU de Grenoble, Pavillon de Neurologie, BP 217, Grenoble Cedex 38043, France e-mail: elhommee@chu-grenoble.fr

${ }^{\dagger}$ Present address:

Alim-Louis Benabid, Clinatec, DRT/LETI, CEA-Grenoble, Grenoble, France;

Pierre Pollak, Service de Neurologie, Hôpitaux Universitaires de Genève, Geneva, Switzerland
Background: Parkinson's disease (PD) is characterized by reduced flexibility, conceptualization, and visuo-spatial abilities. Although these are essential to creativity, case studies show emergence of creativity during PD. Knowledge about the role of dopamine in creativity so far only stems from a few case reports. We aim at demonstrating that creativity can be induced by dopaminergic treatments in PD, and tends to disappear after withdrawal of dopamine agonists.

Methods: Eleven consecutive creative PD patients were selected from candidates for subthalamic nucleus deep brain stimulation (STN DBS) surgery, and compared to 22 noncreative control PD patients. Motor disability (UPDRS III), cognition (Frontal score, Mattis scale), and behavior (Ardouin scale) were assessed before surgery and 1 year after.

Results: Before surgery, whereas cognitive and motor assessments were similar between groups, dopamine agonist (but not levodopa) dosages were higher in creative patients $(p=0.01)$. The Ardouin scale revealed also a specific psycho-behavioral profile of creative patients which had higher scores for mania $(p<0.001)$, hobbyism $(p=0.001)$, nocturnal hyperactivity $(p=0.041)$, appetitive functioning $(p=0.003)$, and ON euphoria $(p=0.007)$ and lower scores for apathy and OFF dysphoria ( $p=0.04$ for each). Post-operative motor, cognitive, and behavioral scores as dopaminergic treatment dosages were equivalent between groups. Motor improvement allowed for a $68.6 \%$ decrease in dopaminergic treatment. Only 1 of the 11 patients remained creative after surgery. Reduction of dopamine agonist was significantly correlated to the decrease in creativity in the whole population of study (Spearman correlation coefficient $\rho=0.47$ with confidence index of $95 \%=0.16$; $0.70, p=0.0053$ ).

Conclusion: Creativity in PD is linked to dopamine agonist therapy, and tends to disappear after STN DBS in parallel to reduction of dopamine agonists, which are relatively selective for the mesolimbic D3 dopamine receptors.

Keywords: STN DBS, impulse control disorders, creativity, dopamine, Parkinson's disease

\section{INTRODUCTION}

For a production to qualify as "creative," it must fulfill two criteria: it must be new (or original) and useful (or valuable, or relevant) (1). However, this both criterions are subjective. A creative work is not the result of a single cognitive process, of neuronal activity in one isolated cerebral area, or of a unique mental faculty, but of the interaction of multiple cognitive processes supported by a large network of multiple cerebral areas. The neurotransmitter dopamine plays a crucial role in this complex interaction. A link seems to exist between mental illness, notably bipolar disorder, dopamine, and creativity. Many well-known artists (e.g., Edward Munch, Ernest Hemingway, and Virginia Woolf) suffered from bipolar disorder and $38.3 \%$ of British artists who received awards were treated for affective disorders (2). A strong dopaminergic component is reported in bipolar disorder, treated by antidopaminergic medication. Many artists admit to being more creative under the influence of psychoactive or "psychedelic" drugs. Drugs that can lead to addiction induce a large release of dopamine in the mesolimbic pathway, directly for amphetamine and cocaine by blocking dopamine reuptake, and indirectly for other psychoactive drugs such as alcohol (3). The dopaminergic mesolimbic pathway is involved in the control of motivational, reward, and reinforcement processes and contributes to dependence and addiction. Eysenck proposed that people in whom the "psychoticism" personality trait is strong, experience a "widening of the associative horizon," which could generate creativity by weakening latent inhibition of thought (4). He also reported a link between psychoticism, which is highly represented 
in mental illness and increased dopamine levels. Flaherty proposed a tridimensional model of creativity, in which frontal, temporal, and dopaminergic systems modulate idea generation and creativity, influenced by medical conditions and treatments $(5,6)$. Two recent neurobiological studies established a link between dopamine and creativity $(7,8)$. In Parkinson's disease (PD), (i) depletion of the substantia nigra and the ventral tegmental area causes low dopamine concentration in the brain and (ii) cognitive impairment diminishes flexibility processes essential to creativity. To Lakke's surprise, artistic activity persisted in PD, and in the case of several patients was awakened, from the time of disease onset (9). Many case reports confirm exacerbation or revelation of creative art work in PD patients treated by dopamine replacement therapy (DRT) and especially dopamine agonists (10-13). Very thoughtfully and exhaustive reviews sustain strongly the link between dopaminergic treatment and awakening of creativity in $\mathrm{PD}$, but to date, there is only case report and no group study permitting to support this assertion $(6,14)$. Deep brain stimulation (DBS) of the subthalamic nucleus (STN) allows reduction of DRT by $50 \%$ on average, maintaining a stable and relatively good motor state (15). STN stimulation in PD allows longitudinal monitoring of the consequences of dopamine modulation on creativity and other motivational behaviors (16). DBS targets the sensorimotor part of the STN, which depends on the nigrostriatal dopaminergic pathway. The limbic part of the STN, which depends on the mesolimbic dopaminergic pathway, is less influenced by DBS. STN DBS thus can indirectly unmask non-motor symptoms related to lesions in the mesolimbic dopaminergic system (17). We conducted a case controlled comparative study in PD patients undergoing STN DBS surgery to assess the influence of DRT on creativity. By comparing psychological features in creative and non-creative patients, we aimed to describe the potential individual co-variables of creativity, particularly hypomanic mood and impulse control disorders, which are also modulated by DRT.

\section{MATERIALS AND METHODS \\ STUDY POPULATION AND DESIGN}

A total of 76 consecutive patients underwent bilateral STN DBS in Grenoble between December 2004 and August 2007. Selection criteria for surgery were: (i) clinically diagnosed PD; (ii) severe LDOPA-related motor complications despite optimal adjustment of anti-Parkinsonian medication; (iii) age under 70 years; and (iv) absence of surgical contraindications, dementia, or major ongoing psychiatric illness (18). Eleven patients fulfilled the study's specific inclusion criteria, i.e., had a score $\geq 2$ for the "creativity" item of the Ardouin scale $(16,19)$. For each identified creative case, two PD controls with no significant creative behavior ("creativity" $\leq 1$ on the Ardouin scale) were selected. These PD controls had undergone STN DBS surgery immediately before and immediately after the identified case. The sample's characteristics are described in Table 1. Assessments took place in the month preceding surgery and 1 year $( \pm 1$ month) later. Exhaustive evaluations of mood, behavior, and cognition were carried out during routine hospital visits by a clinical neuropsychologist experienced in the assessment of neuropsychiatric symptoms in PD. All evaluations were conducted prospectively; data collection was retrospective.
We added a case report to illustrate the changes in creative behavior related to dopamine agonist modifications.

\section{OUTCOME MEASURES \\ Motor outcome and treatment}

Dopaminergic treatment was expressed in (i) daily dopamine agonist equivalent dose, (ii) daily L-DOPA dose, and (iii) total daily dopamine equivalent dose. Dopamine agonist equivalent dose was calculated by comparison to $100 \mathrm{mg} \mathrm{L}-\mathrm{DOPA}$ in terms of motor anti-Parkinsonian effect (18). Total daily dopamine equivalent dose is the sum of dopamine agonist equivalent and L-DOPA doses. Psychotropic medication (atypical neuroleptic, antidepressant, benzodiazepine, sleeping pills) was noted. Chronic stimulation parameters were noted at post-operative follow-up. The Unified Parkinson's Disease Rating Scale part III (motor score) was used to assess the beneficial effects of L-DOPA and subthalamic stimulation on Parkinsonian motor signs (20). Before surgery, UPDRS III was evaluated in OFF and ON medication conditions using suprathreshold doses of L-DOPA (18). This assessment was repeated at follow-up, in four treatment conditions (OFF medication/ON stimulation; OFF medication/OFF stimulation; $\mathrm{ON}$ medication/OFF stimulation; ON medication/ON stimulation).

\section{Cognitive evaluation}

Overall cognitive function was assessed using the Mattis dementia rating scale (21). The degree of frontal-subcortical deterioration was evaluated using the frontal score, a more specific test battery measuring frontal executive function (22). Assessment included the simplified version of the Wisconsin Card Sorting Test (23), verbal fluency tests (24), and graphic and motor series (25).

\section{Evaluation of mood and behavior}

Ardouin scale. This previously described instrument (19) is currently undergoing validation in PD (Rieu et al., submitted). Patients' general psychological state is assessed (depressive, hypomanic or manic mood, anxiety, irritability, hyper-emotivity, and psychotic symptomatology), as are apathy, non-motor fluctuations (non-motor $\mathrm{ON}$ and non-motor $\mathrm{OFF}$ ), and hyperdopaminergic behaviors (12 items: nocturnal hyperactivity, diurnal somnolence, excessive eating, creativity, hobbyism, punding, risk-seeking behavior, compulsive shopping, pathological gambling, hypersexuality, compulsive dopaminergic medication use, and overall functioning in an appetitive mode). The frequency and intensity of a symptom's occurrence in the preceding month is rated on a scale ranging from 0 (absent) to 4 (severe). A score of 0 indicates no modification of the patient's usual habits; a score of 1 reflects slight modification; a score of 2 is indicative of a moderate modification in habitual behavior that is usually significant enough to require therapeutic adjustment; and a score $>2$ equates with clear-cut maladaptive pathological behavior requiring immediate therapeutic intervention. All 11 creative patients scored $\geq 2$ on the "creativity" item, and had experienced a recent emergence of or increase in creative activity, accompanied by an addictive drivingforce (e.g., individuals pursued the creative activity for longer than initially intended, especially at night; their daily activity revolved around creativity, and considerable time was devoted to it; other behavioral repertoires, such as meals, social, occupational, and 
Table 1 | Patients' characteristics before and 1 year after surgery, expressed by median (25th; 75th percentile).

\begin{tabular}{|c|c|c|c|c|c|c|}
\hline & \multicolumn{3}{|c|}{ Before surgery } & \multicolumn{3}{|c|}{1 year after surgery } \\
\hline & $\begin{array}{l}\text { Creative group } \\
(n=11)\end{array}$ & $\begin{array}{l}\text { Control group } \\
(n=22)\end{array}$ & $p$ & $\begin{array}{l}\text { Creative group } \\
(n=11)\end{array}$ & $\begin{array}{l}\text { Control group } \\
(n=22)\end{array}$ & $p$ \\
\hline \multicolumn{7}{|l|}{ GENERAL CHARACTERISTICS } \\
\hline Sex (\% of female) & $45.5 \%$ & $31.8 \%$ & 0.443 & - & - & \\
\hline Age (years) & $53(51 ; 57)$ & $56.5(52 ; 63)$ & 0.358 & - & - & \\
\hline Hemi body onset of PD (\% of L/R/Bilat.) & $(45 / 50 / 5)$ & $(55 / 45 / 0)$ & & & & \\
\hline DRT treatment duration (years) & $10(7 ; 12)$ & $9.5(7 ; 13)$ & 0.673 & - & - & \\
\hline Education (years) & $12(9 ; 17)$ & $9(9 ; 14)$ & 0.160 & - & - & \\
\hline \multicolumn{7}{|l|}{ DRT } \\
\hline Dopamine agonist equivalent dose (mg/day) & $400(350 ; 500)$ & $300(180 ; 320)$ & 0.012 & $120(0 ; 210)$ & $37.5(0 ; 400)$ & 0.952 \\
\hline \multicolumn{7}{|l|}{ MOTOR OUTCOME } \\
\hline UPDRS III ON medication /108 & $9.5(8 ; 12)$ & $8.5(5 ; 10.5)$ & 0.130 & $8(5 ; 17.5)$ & $10.8(6.5 ; 18)$ & 0.359 \\
\hline UPDRS III OFF medication /108 & $36(33 ; 41)$ & $36(28 ; 43)$ & 0.909 & $11(8 ; 28)$ & $15.5(11.5 ; 25)$ & 0.422 \\
\hline \multicolumn{7}{|l|}{ COGNITIVE OUTCOME } \\
\hline Mattis dementia rating scale /144 & $141(140 ; 143)$ & $137.5(132 ; 140)$ & 0.018 & $141(138 ; 142)$ & $136.5(130 ; 140)$ & 0.043 \\
\hline Attention /37 & $36(35 ; 37)$ & $35.5(35 ; 36)$ & 0.303 & $36(35 ; 37)$ & $35.5(35 ; 36)$ & 0.440 \\
\hline Initiation /37 & $37(37 ; 37)$ & $35.5(34 ; 37)$ & 0.022 & $37(35 ; 37)$ & $33.5(29 ; 37)$ & 0.022 \\
\hline Construction /6 & $6(6 ; 6)$ & $6(6 ; 6)$ & 0.480 & $6(6 ; 6)$ & $6(6 ; 6)$ & 1.000 \\
\hline Conceptualization /39 & $38(36 ; 39)$ & $37(36 ; 38)$ & 0.329 & $39(38 ; 39)$ & $37.5(34 ; 39)$ & 0.077 \\
\hline Memory /25 & $24(24 ; 25)$ & $24(22 ; 25)$ & 0.443 & $24(23 ; 25)$ & $25(23 ; 25)$ & 0.566 \\
\hline Frontal score /50 & $41.9(41 ; 46.6)$ & $37.3(29.5 ; 43.5)$ & 0.136 & $41.8(40.3 ; 44.7)$ & $39.5(29.8 ; 45)$ & 0.340 \\
\hline Wisconsin Card Sorting Test /20 & $15(15 ; 20)$ & $12(9 ; 18)$ & 0.085 & $18(15 ; 20)$ & $16.5(9 ; 18)$ & 0.082 \\
\hline Verbal fluency /10 & $8.6(7.7 ; 10)$ & $8.3(7 ; 10)$ & 0.493 & $6.7(6.3 ; 8.3)$ & $7(5.3 ; 9)$ & 0.939 \\
\hline Motor series /10 & $10(9.2 ; 10)$ & $9.3(6.1 ; 10)$ & 0.076 & $8.6(7.4 ; 10)$ & $9.3(6.8 ; 10)$ & 0.937 \\
\hline Graphic series /10 & $7(6.2 ; 10)$ & $7(5 ; 10)$ & 0.433 & $10(6.2 ; 10)$ & $8.8(5 ; 10)$ & 0.434 \\
\hline \multicolumn{7}{|l|}{ APATHY AND DEPRESSION } \\
\hline Beck depression inventory /63 & $6(1 ; 8)$ & $10(8 ; 17)$ & 0.002 & $8(6 ; 9)$ & $6.5(3 ; 11)$ & 0.455 \\
\hline Starkstein apathy scale /42 & $5(2 ; 7)$ & $8.5(5 ; 12)$ & 0.021 & $10(7 ; 13)$ & $14(10 ; 17)$ & 0.283 \\
\hline
\end{tabular}

After surgery, evaluations are made under chronic stimulation parameters.

recreational activities were abandoned in favor of the creative activity, as were family or professional obligations).

Beck depression inventory II. The Beck depression inventory (BDI), a self-reported scale validated in $\mathrm{PD}$, was used to determine the severity of depressive symptoms $(26,27)$.

Starkstein apathy scale. Since a lack of motivation is often observed in the post-operative year following STN DBS (17), and probably influences the desire to engage in creative activity, the Starkstein apathy scale was used to measure motivation $(28,29)$.

\section{Statistical analyses}

Categorical parameters were summarized in terms of size and frequency, and continuous parameters by median and 25th; 75th percentiles. A Mann-Whitney test was performed on all parameters, in creative and control groups before surgery and 1 year after surgery. A Wilcoxon test was used to compare each of the all variables before surgery and 1 year after, in both groups. Independence between qualitative parameters was assessed using the chi-square test. A non-parametric Spearman test was completed to evaluate rank correlation coefficient. $p$-Values $<0.05$ were considered statistically significant. Statistical analyses were performed using STATA release 12 (StataCorp, College Station, TX, USA) PC-software.

\section{RESULTS}

The general characteristics of the patients are shown in Table $\mathbf{1}$.

In creative patients, artistic work either started when taking DRT $(n=6)$ or pre-existing creativity was markedly exacerbated after the introduction of DRT $(n=5)$. Art work consisted of sculpting $(n=1)$, face casting $(n=1)$, painting $(n=3)$, glass painting $(n=1)$, drawing $(n=1)$, graphic design $(n=1)$, and writing (poetry $n=1$, history book $n=1$, short stories $n=1$ ). Two patients in the control group had a "creativity" item score $=1$, 
indicating a slight recent emergence or exacerbation of creative activity.

While creative and control patients' total DRT dosages were the same, creative patients' dopamine agonist equivalent doses were higher than controls' at baseline (Table 1). Motor improvement permitted post-operative reduction in dopamine agonist equivalent and total DRT equivalent doses to the same extent in both groups, i.e., by $68.6 \%$ on average: L-DOPA daily dose was reduced from 885 to $100 \mathrm{mg} /$ day $(p=0.008)$ in the creative group and from 1070 to $75 \mathrm{mg} /$ day in the control group ( $p \leq 0.001$ ); similarly, daily dopamine agonist equivalent dose was reduced from 400 to $120 \mathrm{mg} /$ day in the creative group $(p=0.014)$ and from 300 to $37.5 \mathrm{mg} /$ day in the control group $(p=0.240)$. Reduction of dopamine agonist was significantly correlated to reduction of creativity in the whole population of study [Spearman correlation coefficient $\rho=0.47$ with confidence index of $95 \%=0.16 ; 0.70$, $p=0.0053]$.

Eleven patients in the creative group were taking dopamine agonists at preoperative assessment, $6 / 11$ were treated by ropinirole, $3 / 11$ by piribedil, $1 / 11$ by pramipexole, and $1 / 11$ by pergolide. One patient in the creative group was taking amantadine. Eighteen of 22 patients in the control group were taking dopamine agonists at preoperative assessment, $4 / 22$ were treated by ropinirole, $5 / 22$ by piribedil, $3 / 22$ by pramipexole, and $6 / 22$ by pergolide. Five patients in the control group were taking amantadine. Thirty-three patients were treated by L-DOPA before surgery. At post-operative assessment, $7 / 11$ creative patients were treated by L-DOPA, and 14/22 control patients. Seven of 11 creative patients were treated by dopamine agonists (3/7 ropinirole, $2 / 7$ piribedil, and $2 / 7$ pramipexole) vs. $10 / 22$ control patients ( $1 / 10$ ropinirole, $8 / 10$ piribedil, $1 / 10$ bromocriptine). Median dosages are presented in Table 1. Stimulation parameters did not differ between groups and were similar for both hemispheres, with a mean $( \pm S D)$ stimulation strength of $2.9 \pm 0.4 \mathrm{~V}$ in creative patients vs. $3.1 \pm 0.4$ in control patients, a median (25th-75th) frequency of 130 (130145) $\mathrm{Hz}$ in the creative group vs. 130 (130-145) in the control group, and a median (25th-75th) pulse duration of 60 (60-60) $\mu \mathrm{s}$ in the creative group vs. $60(60-75)$ in the control group. In each group, one patient was on clozapine, an atypical neuroleptic (Table 2). Creative patients were more frequently treated by antidepressants and benzodiazepines than control patients from baseline (Table 2). The small sample size does not, however, permit statistical analysis.

Table 2 | Psychotropic sedative drugs.

\begin{tabular}{lll}
\hline & Before surgery & 1Year after surgery \\
\hline Creative patients $(n=11)$ & Neuroleptic: $n=1$ & Neuroleptic: $n=1$ \\
& Antidepressant: $n=4$ & Antidepressant: $n=3$ \\
& Benzodiazepine: $n=4$ & Benzodiazepine: $n=4$ \\
& Soporific: $n=0$ & Soporific: $n=0$ \\
Control patients $(n=22)$ & Neuroleptic: $n=1$ & Neuroleptic: $n=1$ \\
& Antidepressant: $n=1$ & Antidepressant: $n=2$ \\
& Benzodiazepine: $n=0$ & Benzodiazepine: $n=2$ \\
& Soporific: $n=2$ & Soporific: $n=0$
\end{tabular}

At preoperative and post-operative assessments, $\mathrm{ON}$ and $\mathrm{OFF}$ medication conditions for UPDRS motor scores did not differ between groups (Table 1). Post-operative improvement in UPDRS motor score in off drug on stimulation condition was superior by $50 \%$ on average.

Overall cognitive function performance was better in creative patients than in controls, with higher scores in the "initiation" subscale of the Mattis dementia rating scale, which measures verbal fluency and graphic automatisms (Table 1). There was no difference in executive function scores in the two groups. Verbal fluency decreased in all patients following surgery: median scores went from $8.6 / 10$ to $6.7 / 10$ in creative patients $(p=0.029)$ and from $8.3 / 10$ to $7 / 10$ in control patients $(p=0.003)$.

Before surgery, creative patients exhibited a specific pattern of hyperdopaminergic behaviors at the Ardouin scale (Table 3): they were more hypomanic, more active at night, had higher scores on "hobbyism," and functioned in a more markedly appetitive mode than control patients. They were less apathetic. They had more pronounced non-motor ONs phases (they experienced greater artificial euphoria during $\mathrm{ON}$ phases), and less severe non-motor OFFs phases (they were less dysphoric, anxious, tired during OFF phases). One year after surgery, overall differences between creative and control patients had diminished: creativity and appetitive functioning were still more highly represented in the creative group, but there were no longer any differences in the other variables. One year after surgery, following the reduction in dopaminergic treatment, creative patients were less hypomanic $(p=0.004)$, more apathetic $(p=0.016)$, non-motor ON had diminished $(p=0.003)$ as had nocturnal hyperactivity $(p=0.015)$, creativity $(p=0.002)$, hobbyism $(p=0.004)$, and appetitive functioning $(p=0.003)$. Hyperdopaminergic behaviors also diminished in control patients. One year after surgery, clinically relevant creative behavior persisted in only 1 of the 11 patients.

Before surgery, creative patients had lower scores for depressive mood than control patients $(p=0.002)$ at the BDI. After surgery, there was no difference between groups. Before surgery, creative patients were less apathetic than control patients $(p=0.021)$. After surgery, apathy scores increased in both groups: from 5 to 10 in creative patients $(p=0.003)$ and from 8.5 to 14 in control patients $(p=0.049)$ (Table 1).

\section{CASE REPORT}

The case of this woman illustrates the influence of dopamine agonists on creativity. PD started in 1994, at age 41, with pain in the right arm. She developed a depressive syndrome on learning the PD diagnosis. A few years later, on a high dose of pramipexole $(2.8 \mathrm{mg} /$ day) associated with levodopa (daily equivalent dose of levodopa $=1100 \mathrm{mg} /$ day), she experienced strong exacerbation of her painting activity (Figure 1), accompanied by nocturnal hyperactivity and psychosis. Dopaminergic addiction followed, as did an escalation to painting addiction (Figures 2-4), associated with compulsive buying of painting material and risktaking behavior. Her life-style changed completely, and her home became a gathering place where her artist friends met up and partied. All the behavioral modifications she experienced had major repercussions, upsetting her personal, family, and social 
Table 3 | Ardouin scale scores expressed by median (25th; 75th percentile) before and 1 year after surgery.

Before surgery

\begin{tabular}{ll}
\hline Creative group & Control group \\
$(n=11)$ & $p$
\end{tabular}

1 year after surgery

\begin{tabular}{ll}
\hline Creative group & $\begin{array}{l}\text { Control group } \\
(n=11)\end{array}$ \\
$(n=22)$
\end{tabular}

\begin{tabular}{|c|c|c|c|c|c|c|}
\hline \multicolumn{7}{|l|}{ GENERAL PSYCHOLOGICAL STATE } \\
\hline Depressive mood & $0(0 ; 1)$ & $0(0 ; 1)$ & 0.883 & $0(0 ; 1)$ & $0(0 ; 1)$ & 0.795 \\
\hline Hypomanic or manic mood & $1(1 ; 2)$ & $0(0 ; 0)$ & $\leq 0.001$ & $0(0 ; 0)$ & $0(0 ; 0)$ & 1.000 \\
\hline Irritability & $0(0 ; 1)$ & $0(0 ; 1)$ & 0.760 & $0(0 ; 1)$ & $0(0 ; 0)$ & 0.647 \\
\hline Hyper-emotivity & $0(0 ; 1)$ & $1(0 ; 2)$ & 0.196 & $0(0 ; 0)$ & $0.5(0 ; 1)$ & 0.057 \\
\hline Psychotic symptomatology & $0(0 ; 0)$ & $0(0 ; 1)$ & 0.373 & $0(0 ; 0)$ & $0(0 ; 0)$ & 0.437 \\
\hline Apathy & $0(0 ; 0)$ & $0(0 ; 1)$ & 0.040 & $1(0 ; 2)$ & $0.5(0 ; 2)$ & 0.759 \\
\hline \multicolumn{7}{|l|}{ NON-MOTOR FLUCTUATIONS } \\
\hline Non-motor ON & $2(2 ; 3)$ & $1(0 ; 2)$ & 0.007 & $0(0 ; 0)$ & $0(0 ; 0)$ & 0.310 \\
\hline Non-motor OFF & $0(0 ; 2)$ & $1(1 ; 3)$ & 0.040 & $0(0 ; 0)$ & $0(0 ; 1)$ & 0.185 \\
\hline \multicolumn{7}{|l|}{ HYPERDOPAMINERGIC BEHAVIOURS } \\
\hline Nocturnal hyperactivity & $1(0 ; 3)$ & $0(0 ; 0)$ & 0.041 & $0(0 ; 0)$ & $0(0 ; 0)$ & 0.480 \\
\hline Hobbyism & $3(1 ; 3)$ & $0(0 ; 1)$ & 0.001 & $0(0 ; 0)$ & $0(0 ; 0)$ & 0.157 \\
\hline Punding & $0(0 ; 0)$ & $0(0 ; 0)$ & 0.611 & $0(0 ; 0)$ & $0(0 ; 0)$ & 1 \\
\hline Risk-seeking behaviour & $0(0 ; 1)$ & $0(0 ; 0)$ & 0.538 & $0(0 ; 1)$ & $0(0 ; 0)$ & 0.012 \\
\hline Compulsive shopping & $0(0 ; 1)$ & $0(0 ; 0)$ & 0.574 & $0(0 ; 0)$ & $0(0 ; 0)$ & 0.480 \\
\hline Pathological gambling & $0(0 ; 0)$ & $0(0 ; 0)$ & 0.206 & $0(0 ; 0)$ & $0(0 ; 0)$ & 0.480 \\
\hline Hypersexuality & $0(0 ; 1)$ & $0(0 ; 1)$ & 0.653 & $0(0 ; 0)$ & $0(0 ; 0)$ & 0.206 \\
\hline Compulsive dopaminergic medication use & $1(0 ; 2)$ & $0(0 ; 2)$ & 0.493 & $0(0 ; 0)$ & $0(0 ; 0)$ & 0.710 \\
\hline Overall functioning in an appetitive mode & $2(2 ; 3)$ & $1(0 ; 1)$ & 0.003 & $0(0 ; 1)$ & $0(0 ; 0)$ & 0.005 \\
\hline
\end{tabular}

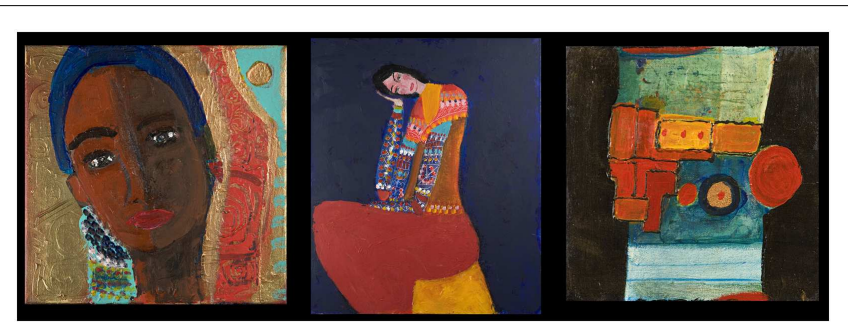

FIGURE 1 | Three works from her first, non-addictive period.

equilibrium, and led to hospitalization, reduction in dopaminergic treatment, and the introduction of clozapine. A subsequent increase in akinesia required higher doses of levodopa, which in turn induced the onset of motor complications. As a result, STN DBS surgery was performed in 2009. Neurosurgical treatment led to improvement in motor fluctuations and reduction of dopaminergic therapy. Her creative activity remained rich, and was judged by the patient herself to be more tranquil and satisfying. She mostly sculpts now (Figure 5). She did not dare to pick up a paintbrush for a long time. She was afraid of falling prey to the devastating addiction to painting again. Here is her own account: I've always drawn and painted. As an adolescent, I would paint on the walls of my attic. But in 2002, I embraced painting totally (Figure 1). I transformed my home into a studio, with tables and canvases everywhere. I was so happy. My illness got worse in 2004: I stopped working and went on new medication. At that point, I started painting from morning till night, and often all through the night until morning. I was obsessed with painting. I bought huge amounts of materials, and used countless numbers of brushes at a time. I used knives, forks, sponges ... I would gouge open tubes of paint - it was everywhere (Figure 2) ... But I was still in control at that point. Then, the urge to paint became incontrollable. I started painting on the walls, the furniture, even the washing machine (Figure 3). I would paint any surface I came across. I also had my "expression wall" and I could not stop myself from painting and repainting this wall every night in a trance-like state. My uncontrollable creativity had turned into something destructive (Figure 4). My partner could no longer bear it. People close to me realized that I crossed some kind of line into the pathological, and in 2006, at their instigation, I was hospitalized. Today, my doctors have succeeded in getting my medication under control, and my creativity has become more tranquil and structured. It has once again become a pleasure, which upsets no-one (Figure 5) (30).

Works illustrating the periods of the patient's creativity are reproduced with her authorization (Figures 1-5). 


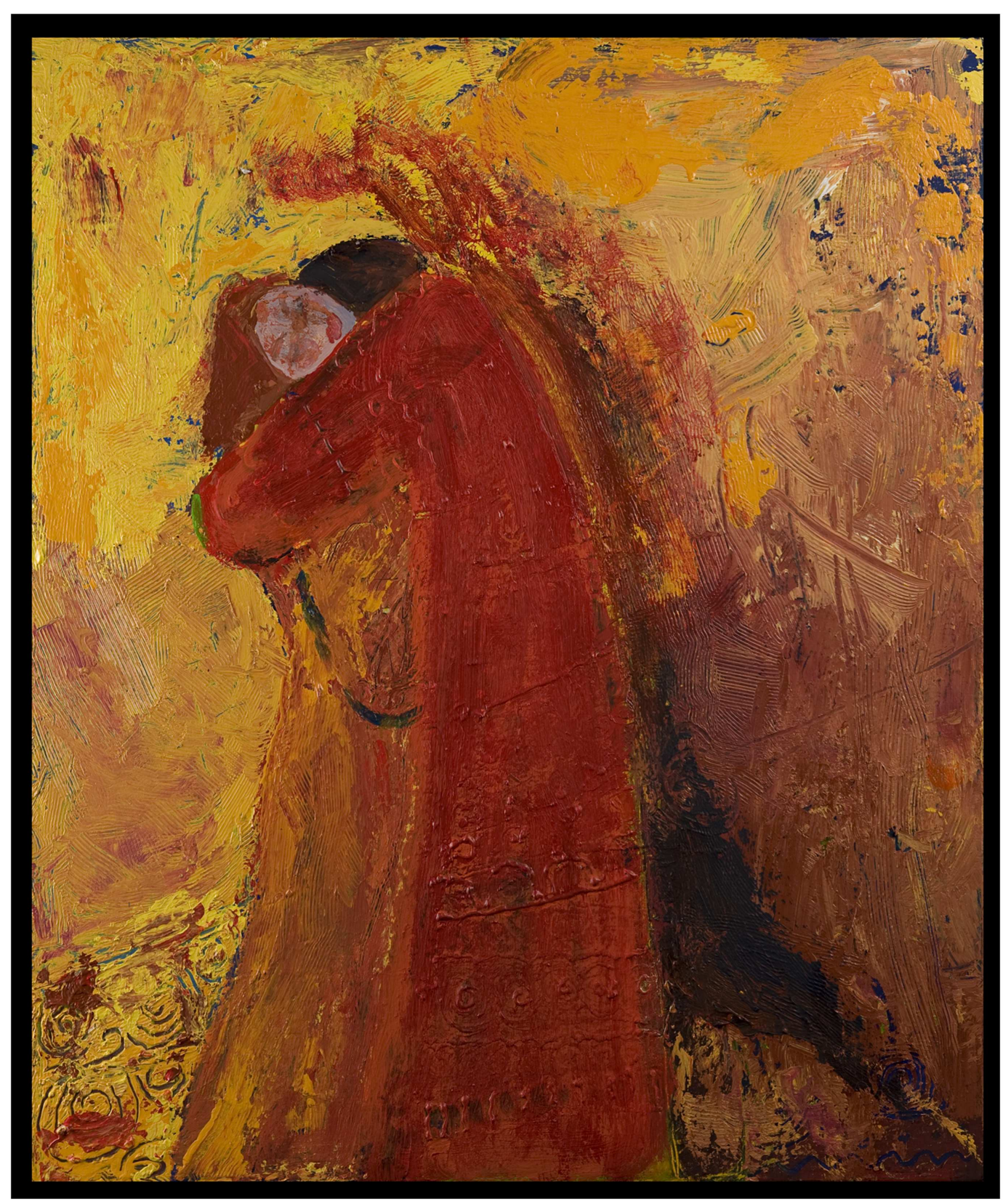

FIGURE 2 | Addictive period. Painting of romantic relationships illustrating the change in content and technique.

\section{DISCUSSION}

\section{FREOUENCY OF CREATIVITY}

Our study revealed a high prevalence of creativity $(14.5 \%)$. This contrasts with the small number of cases reported in the literature to date. The scale used probably enabled easier detection of creativity than do patients' spontaneous accounts of this aspect of their lives, as it systematically evaluates all modifications in behavior. Moreover, surgical candidates are, typically, young, have long disease and treatment durations, and severe motor symptoms justifying high doses of DRT including dopamine agonists which are not recommended for the elderly (31). Hyperdopaminergic behavioral modifications are frequently and commonly observed in this Parkinsonian sub-population. In another, larger cohort, prevalence of creativity was quite similar (16).

\section{CREATIVITY AND PUNDING}

Punding is a frequent behavioral modification in PD, in which prevalence ranges from 0.3 to $14 \%$ and is associated with dopaminergic medications and impulse control disorder (32). Punding describes a heterogeneous set of aimless, stereotyped 


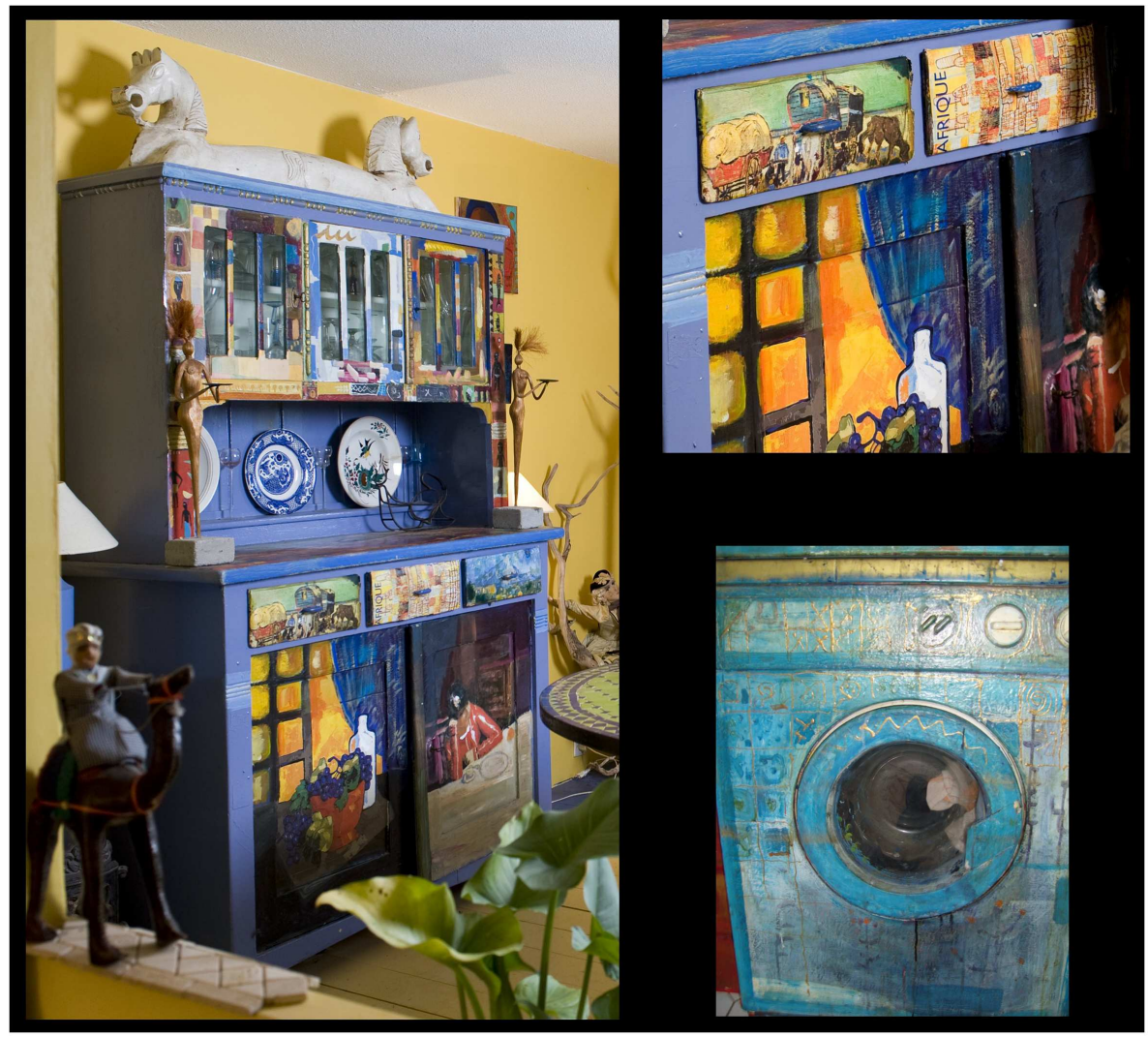

FIGURE 3 |Addictive period. Examples of furniture and equipment being transformed in pieces of art illustrating the change in quantity and in surfaces of application.

behaviors performed for long periods of time at the expense of other activities (33). To our point of view, creativity is the opposite of punding in its fundamental characteristics: by definition, creativity implies: (i) novelty, not repetitiveness and (ii) usefulness, not aimlessness. In fact, punding is even discussed to be included in the rubric of stereotypies (34).

\section{LINK BETWEEN CREATIVITY AND DOPAMINE AGONISTS}

Reduction of creativity was correlated with decrease in dopamine agonists' drugs. Creative patients took higher doses of dopamine agonists than control patients before surgery. Both groups were, however, similar in terms of severity of motor symptomatology, and stage of disease. It seems that, as has been demonstrated for other behavioral modifications, dopaminergic agonists play a crucial role in the occurrence of addictive appetence to pleasure, whether it concerns creative behavior, gambling, shopping, eating, or sexual activity (35). Obviously, creativity belongs to activities driven by the reward system.

Because of their high affinity with D3 receptors which are mainly expressed in the mesolimbic pathway, like psychedelic drugs, currently available D2-D3 dopamine agonists may facilitate creative ideas and their expression. It seems plausible that dopamine agonists encourage greater freedom of association and artistic production.
Artists such as Jack Kerouac, Jean-Paul Sartre, Johnny Cash, or Andy Wharhol, who all used amphetamines to facilitate creative inspiration in their specific artistic domains can be cited to illustrate our point of view. Jack Kerouac typed his best-seller "On the road" in 3 weeks, working day and night, on a continuous roll of paper, chosen to avoid interrupting his rhythm, in a creative "trance" that he could not bear to break by changing the paper in his typewriter. Amphetamines induce an acute increase in dopamine in the accumbens shell (36), which expresses the D3 receptor (37). While pharmacological, neuro-anatomical, and genetic data suggest a crucial role of the $\mathrm{D} 3$ receptor in pharmacodependence (38), it would also be interesting to study its implication in behavioral addictions which seem to have a mechanism in common with drug addiction (16).

Dopamine agonists can induce hallucinations in which static objects change into moving or living objects. They are therefore likely to alter perception and perhaps facilitate visual inspiration (39).

Moreover, by acting on the nucleus accumbens, one of the main components of cerebral reward circuits (40), dopamine agonists probably encourage positive feedback on the creative artist's own work, which makes presenting his/her work to others easier due to increased self-confidence, audacity, and non-conformism. This is compatible with the individual psychological predispositions 


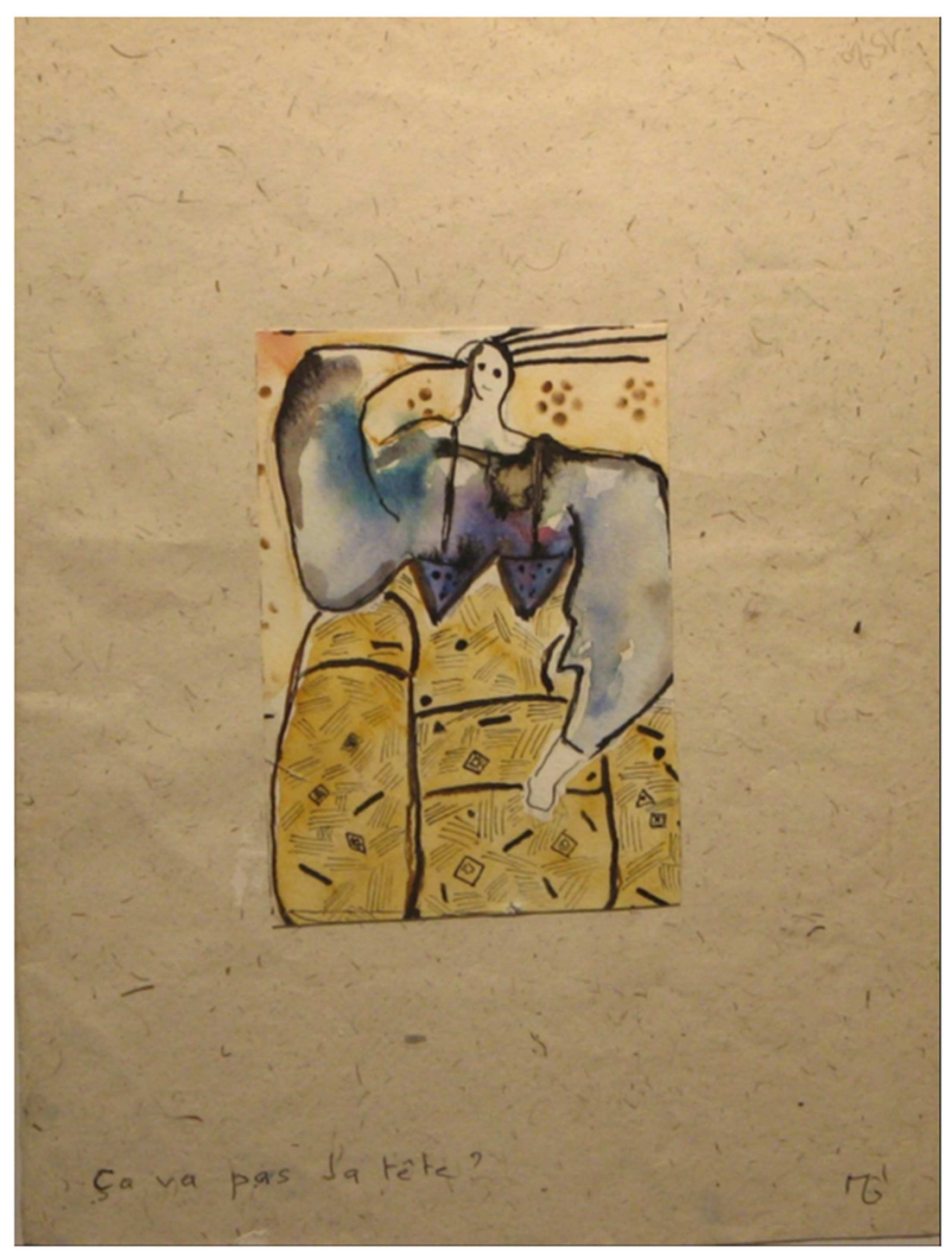

FIGURE 4 | Addictive period. The painting bears the inscription "Am I going nuts?" illustrating maintenance of self-criticism by the patient.

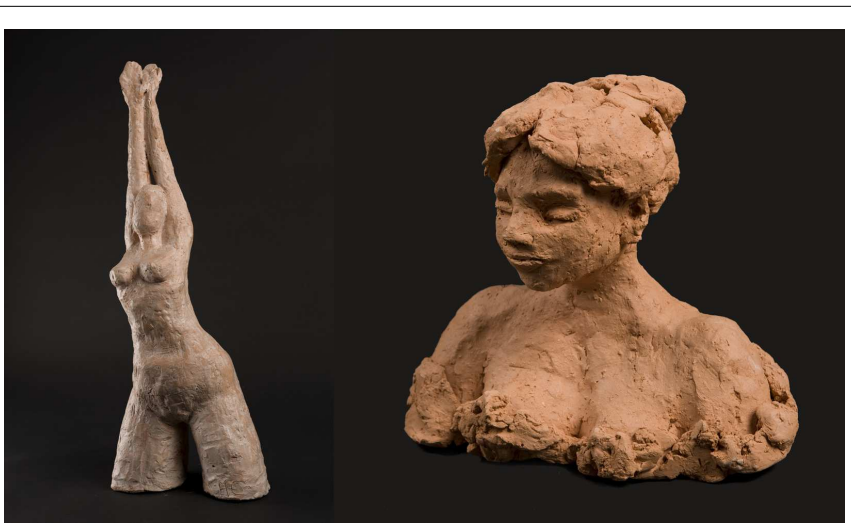

FIGURE 5 | Resumption of a calm and satisfying creativity of our creative patients, who were indeed more hypomanic than control patients.

Finally, mesolimbic denervation leads, via compensatory mechanisms, to increased sensitivity to the psychostimulant effects of dopaminergic treatment, as has been shown in the animal model of dopaminergic lesions treated with dopaminergic drugs $(41,42)$. This is analogous with the higher propensity of PD patients with more severe nigrostriatal denervation to develop dyskinesia (43).

\section{CREATIVITY REVERSAL AFTER REDUCTION OF DOPAMINERGIC} THERAPY

We demonstrated indirectly that creativity is at least partly dopamine dependent, since it diminished significantly following reduction in dopaminergic treatment permitted by STN stimulation. Only 1 of our 11 creative patients continued to maintain a high level of creativity 1 year after surgery. Patients who 
immerse themselves in creativity are typically convinced that their passion is the expression of their own personality and not influenced by the drugs they are taking to treat Parkinsonism. They are attached to their creativity, since it is a source of strong personal enrichment, an "awakening" that is socially recognized (unless it escalates to addictive pathological behavior, as in our case study). When surgery is envisaged by medical staff, creative patients should be warned that it could, as observed in this study, induce a decrease in creative activity via the reduction in dopaminergic treatment. If treatment is maintained, the cumulative effects of stimulation and dopamine agonists could exacerbate creativity (44), and other hyperdopaminergic behaviors (45). The creativity-dopamine agonist therapy link and the absence of difference between both hemisphere parameters of STN DBS we found do not support previous work showing an acute and lateralized direct annihilating effect of STN DBS on creativity in an isolated PD patient (46). Reduction in DRT, especially dopamine agonists, permitted by STN DBS induces not only a decrease in creativity, but also an overall decrease in motivated behaviors (16) reaching severe apathy level (17). Dopaminergic treatment seems to influence all goal-directed behaviors with a reward component, contrary to the disease itself which leads to loss of motivation related to mesolimbic dopaminergic denervation (17). This explains the continuum of observed behaviors in PD with awakening of the desire to undertake pleasant activities if the mesolimbic system is rich in dopamine, and extinction of the desire to undertake pleasant activities if the mesolimbic system lacks dopamine.

\section{PSYCHOLOGICAL PROFILE OF CREATIVE PATIENTS}

Creative patients are more hypomanic, more active at night; they pursue more other hobbies and function in a more appetitive mode than controls. They are also less apathetic and experience more pronounced ON euphoria and less severe OFF dysphoria. This profile corresponds to an enthusiastic and energetic personality, with a proliferation of ideas and desires, an ease of association, a less conventional way of thinking, good levels of self-confidence, and belief in their capacity to accomplish great things. We suggest that there may be a link between the high prevalence of creativity in PD patients with a hypomanic profile and bipolar disorder which is also associated with creativity (47). We wonder if it would be legitimate to make an analogy between bipolar disorder and fluctuating PD patients, who are subject to repeated, ultra-rapid mood cycles parallel to motor fluctuations, in the same day. Creative patients in our study were taking more dopamine agonists and antidepressant and anxiolytic drugs. Could their medication actually cover up more severe non-motor OFFs requiring higher doses and association of medication than those of control patients? PD and bipolar disorder both lead to over-expression of creative talent, favoring the hypothesis that mesolimbic dopaminergic system dysfunction is a mechanism of bipolar disorder as it is the case in PD.

Creative patients did not necessarily present more impulse control disorders or L-DOPA addiction than controls, on the contrary, although they have higher doses of dopamine agonist. This result is compatible with the absence of association between artistic creativity and impulsivity or impulse control disorder observed by Canesi et al. (48), in contrast to other work showing that involvement in a creative or artistic profession can be a potential risk to develop impulse control disorder in PD (49).

\section{OTHER FACTORS EXPLAINING CREATIVITY}

Given the importance of a well-functioning prefrontal cortex for creativity exist, it is conceivable that the bilateral insertion into the frontal lobe of microelectrodes and DBS leads has an impact on creativity. This would count for cases as well as controls, but since the controls were already not creative before surgery, decreased creativity would not be evident in this group. However, our data showed a good maintain of frontal score (superior to 40/50, which is good) both in cases and controls after surgery.

When examining the influence of the side of the body onset of $\mathrm{PD}$, we did not find any association with creativity, on the contrary to previous work (50).

Dopamine agonists probably facilitate creativity, but do not generate it on their own. Non-neurobiological factors favoring creativity in PD should also be investigated in order to advance research in this domain. $\mathrm{PD}$ patients need to communicate by unconventional means of expression in order to face up to their pathology which is often difficult for their relatives to understand, and socially stigmatized. Onset of PD generally occurs around retirement age and Parkinson-related disability may also lead to premature discontinuation of professional activity. Retirement is usually the time to enjoy life and realize longstanding dreams of youth. Psychodynamic models also explain creativity in $\mathrm{PD}$, as a need to sublimate the accumulation of all the large and small frustrations of living with PD every day: inability to carry out plans, being made fun of in public, being unable to wear the same clothes anymore, no longer being able to perform certain dance steps, being discouraged from driving a car. Art is the expression of the soul and the PD patient's soul has a lot to express.

\section{LIMITS}

Our work provides the first group study linking creativity to dopamine agonists' therapy in PD. However, the present study has several methodological and conceptual limits. The sample sizes are relatively small, and can question the generalization of our results to PD candidates to surgery and to PD in general. However, we present convincing statistically significant results on this small population of selected patients to surgery. We propose to generalize our results to PD patients without relevant executive dysfunction (as it is the case in patients selected for STN DBS) and exposed to dopamine agonists. In spite of PD, these patients conserve good cortico-cortical projection functioning. We do not intend to generalize our results to cognitively impaired PD patients, with important spread of alpha-synucleinopathy in the different cortical areas (51). Even if exposed to dopamine agonists, these cognitively impaired patients might not develop creativity, because they are lacking the basis of creative acts: concept elaboration, fluency, mental flexibility, i.e., intact executive function (52). Furthermore, creativity was evaluated on a single item on a single scale. However, no specific validated tool does exist in the context of $\mathrm{PD}$. The existing psychometric divergent thinking battery that was used in PD, the Torrance Test of Creative Thinking did not permit to differentiate creative PD patients from healthy controls without creativity, which questions its validity (48). 


\section{CONCLUSION}

Creative patients have higher doses of dopamine agonists than controls presenting the same motor severity. Creativity appears with, or is exacerbated by, dopaminergic treatment, and decreases when dopaminergic treatment is reduced, in the context of STN stimulation. Dopamine agonists have a more selective affinity with D3 dopaminergic receptors, which are more highly represented in the mesolimbic system, than L-DOPA which has a more diffuse and balanced action on all dopaminergic receptors. Overstimulation of mesolimbic dopaminergic systems seems to facilitate the drive to create in PD patients who possess a certain "creative intelligence," in a non-specific way, via the enhancement of all directed behaviors with a reward component. Dopaminergic treatment in PD induces ultra-rapid mood cycles, with euphoric/dysphoric oscillations, constituting a favorable ground for creativity, as it is the case in bipolar disorder. While behavioral addictions and impulse control disorders are well-known potentially devastating side effects, creativity can generally be considered as a highly beneficial side effect of dopamine agonists.

\section{AUTHOR CONTRIBUTIONS}

Eugénie Lhommée and Alina Batir: substantial contributions to conception and design, acquisition of data, analysis and interpretation of data, drafting the article, final approval of the version to be published. Jean-Louis Quesada: substantial contributions to conception and design, analysis and interpretation of data, revising it critically for important intellectual content, final approval of the version to be published. Claire Ardouin: substantial contributions to conception and design, acquisition of data, analysis and interpretation of data, revising it critically for important intellectual content, final approval of the version to be published. Valérie Fraix, Eric Seigneuret, Stéphan Chabardès, and Alim-Louis Benabid: acquisition of data, revising it critically for important intellectual content, final approval of the version to be published. Pierre Pollak: substantial contributions to conception and design, acquisition of data, revising it critically for important intellectual content, final approval of the version to be published. Paul Krack: substantial contributions to conception and design, acquisition of data, analysis and interpretation of data, drafting the article, revising it critically for important intellectual content, final approval of the version to be published.

\section{ACKNOWLEDGMENTS}

We thank France Parkinson association to have funded this work. We thank all PD patients participating in this study, with special thanks to the patient described in the case report. Thanks to Dominique Guillaudin for the photos. We thank Cate DalMolin for English corrections.

\section{REFERENCES}

1. Sternberg RJ. Handbook of Creativity. Cambridge: Cambridge University Press (1999).

2. Jamison KR. Mood disorders and patterns of creativity in British writers and artists. Psychiatry (1989) 52(2):125-34.

3. Wolf ME, Mangiavacchi S, Sun X. Mechanisms by which dopamine receptors may influence synaptic plasticity. Ann N Y Acad Sci (2003) 1003:241-9. doi:10.1196/annals.1300.015

4. Eysenck HJ. Genius: The Natural History of Creativity. Cambridge: Cambridge University Press (1995).
5. Flaherty AW. Frontotemporal and dopaminergic control of idea generation and creative drive. J Comp Neurol (2005) 493(1):147-53. doi:10.1002/cne.20768

6. Flaherty AW. Brain illness and creativity: mechanisms and treatment risks. Can J Psychiatry (2011) 56(3):132-43.

7. de Manzano O, Cervenka S, Karabanov A, Farde L, Ullen F. Thinking outside a less intact box: thalamic dopamine D2 receptor densities are negatively related to psychometric creativity in healthy individuals. PLoS One (2010) 5(5):e10670. doi:10.1371/journal.pone.0010670

8. Chermahini SA, Hommel B. The (b)link between creativity and dopamine: spontaneous eye blink rates predict and dissociate divergent and convergent thinking. Cognition (2010) 115(3):458-65. doi:10.1016/j.cognition.2010.03.007

9. Lakke JP. Art and Parkinson's disease. Adv Neurol (1999) 80:471-9.

10. Kulisevsky J, Pagonabarraga J, Martinez-Corral M. Changes in artistic style and behaviour in Parkinson's disease: dopamine and creativity. J Neurol (2009) 256(5):816-9. doi:10.1007/s00415-009-5001-1

11. Schrag A, Trimble M. Poetic talent unmasked by treatment of Parkinson's disease. Mov Disord (2001) 16(6):1175-6. doi:10.1002/mds.1239

12. Chatterjee A, Hamilton RH, Amorapanth PX. Art produced by a patient with Parkinson's disease. Behav Neurol (2006) 17(2):105-8. doi:10.1155/2006/ 901832

13. Walker RH, Warwick R, Cercy SP. Augmentation of artistic productivity in Parkinson's disease. Mov Disord (2006) 21(2):285-6. doi:10.1002/mds.20758

14. Inzelberg R. The awakening of artistic creativity and Parkinson's disease. Behav Neurosci (2013) 127(2):256-61. doi:10.1037/a0031052

15. Kleiner-Fisman G, Herzog J, Fisman DN, Tamma F, Lyons KE, Pahwa R, et al. Subthalamic nucleus deep brain stimulation: summary and meta-analysis of outcomes. Mov Disord (2006) 21(Suppl 14):S290-304. doi:10.1002/mds.20962

16. Lhommee E, Klinger H, Thobois S, Schmitt E, Ardouin C, Bichon A, et al. Subthalamic stimulation in Parkinson's disease: restoring the balance of motivated behaviours. Brain (2012) 135(Pt 5):1463-77. doi:10.1093/brain/aws078

17. Thobois S, Ardouin C, Lhommee E, Klinger H, Lagrange C, Xie J, et al. Non-motor dopamine withdrawal syndrome after surgery for Parkinson's disease: predictors and underlying mesolimbic denervation. Brain (2010) $133(\mathrm{Pt}$ 4):1111-27. doi:10.1093/brain/awq032

18. Krack P, Batir A, Van Blercom N, Chabardes S, Fraix V, Ardouin C, et al. Five-year follow-up of bilateral stimulation of the subthalamic nucleus in advanced Parkinson's disease. N Engl J Med (2003) 349(20):1925-34. doi:10. 1056/NEJMoa035275

19. Ardouin C, Chereau I, Llorca PM, Lhommee E, Durif F, Pollak P, et al. Assessment of hyper- and hypo-dopaminergic behaviors in Parkinson's disease. Rev Neurol (Paris) (2009) 165(11):845-56 [Article in French]. doi:10.1016/j.neurol. 2009.06.003

20. Fahn S, Elton RL, Fahn S, Marsden CD, Calne D, Goldstein M. Unified Parkinson's Disease Rating Scale. Recent Developments in Parkinson's Disease. Florham Park, NJ: MacMillan Health Care Information (1987). p. 153-63.

21. Mattis S. Dementia Rating Scale: Professional Manual. Odessa, FL: Psychological Assessment Resources Inc. (1988).

22. Pillon B, Dubois B, Lhermitte F, Agid Y. Heterogeneity of cognitive impairment in progressive supranuclear palsy, Parkinson's disease, and Alzheimer's disease. Neurology (1986) 36:1179-85. doi:10.1212/WNL.36.9.1179

23. Nelson HE. A modified card-sorting test sensitive to frontal lobe disease. Cortex (1976) 12:53-60. doi:10.1016/S0010-9452(76)80035-4

24. Cardebat D, Doyon B, Puel M, Goulet P, Joanette Y. Formal and semantic lexical evocation in normal subjects. Performance and dynamics of production as a function of sex, age and educational level. Acta Neurol Belg (1990) 90:207-17 [Article in French].

25. Luria AR. Higher Cortical Functions in Man. New-York, NY: Basic Books (1966). 26. Williams JR, Hirsch ES, Anderson K, Bush AL, Goldstein SR, Grill S, et al. A comparison of nine scales to detect depression in Parkinson disease: which scale to use? Neurology (2012) 78(13):998-1006. doi:10.1212/WNL.0b013e31824d587f

27. Beck AT, Steer RA. Internal consistencies of the original and revised Beck depression inventory. J Clin Psychol (1984) 40(6):1365-7. doi:10.1002/10974679(198411)40:6<1365::AID-JCLP2270400615>3.0.CO;2-D

28. Starkstein SE, Mayberg HS, Preziosi TJ, Andrezejewski P, Leiguarda R, Robinson RG. Reliability, validity, and clinical correlates of apathy in Parkinson's disease. J Neuropsychiatry Clin Neurosci (1992) 4:134-9.

29. Starkstein SE, Merello M, Jorge R, Brockman S, Bruce D, Power B. The syndromal validity and nosological position of apathy in Parkinson's disease. Mov Disord (2009) 24(8):1211-6. doi:10.1002/mds.22577 
30. Musée grenoblois des sciences médicales. Catalogue Published for the Exhibition: Parkinson's, Creativity, Dopamine. Echirolles, France (2010).

31. Olanow CW, Watts RL, Koller WC. An algorithm (decision tree) for the management of Parkinson's disease (2001): treatment guidelines. Neurology (2001) 11(Suppl 5):S1-88. doi:10.1212/WNL.56.suppl_5.S1

32. Spencer AH, Rickards H, Fasano A, Cavanna AE. The prevalence and clinical characteristics of punding in Parkinson's disease. Mov Disord (2011) 26(4):578-86. doi:10.1002/mds.23508

33. Ferrara JM, Stacy M. Impulse-control disorders in Parkinson's disease. CNS Spectr (2008) 13(8):690-8.

34. Fasano A, Evans AH. Is punding a stereotypy? Mov Disord (2013) 28(3):404-5. doi: $10.1002 / \mathrm{mds} .25254$

35. Weintraub D, Koester J, Potenza MN, Siderowf AD, Stacy M, Voon V, et al. Impulse control disorders in Parkinson disease: a cross-sectional study of 3090 patients. Arch Neurol (2010) 67(5):589-95. doi:10.1001/archneurol. 2010.65

36. Di Chiara G, Imperato A. Drugs abused by humans preferentially increase synaptic dopamine concentrations in the mesolimbic system of freely moving rats. Proc Natl Acad Sci U S A (1988) 85(14):5274-8. doi:10.1073/pnas.85. 14.5274

37. Black KJ, Hershey T, Koller JM, Videen TO, Mintun MA, Price JL, et al. A possible substrate for dopamine-related changes in mood and behavior: prefrontal and limbic effects of a D3-preferring dopamine agonist. Proc Natl Acad Sci U S A (2002) 99:17113-8. doi:10.1073/pnas.012260599

38. Koob GF, Volkow ND. Neurocircuitry of addiction. Neuropsychopharmacology (2010) 35(1):217-38. doi:10.1038/npp.2009.110

39. Fenelon G, Mahieux F, Huon R, Ziegler M. Hallucinations in Parkinson's disease: prevalence, phenomenology and risk factors. Brain (2000) 123(Pt 4):733-45. doi:10.1093/brain/123.4.733

40. Koob GF, Le Moal M. Drug addiction, dysregulation of reward, and allostasis. Neuropsychopharmacology (2001) 24(2):97-129. doi:10.1016/S0893-133X(00) 00195-0

41. Ungerstedt U. Adipsia and aphagia after 6-hydroxydopamine induced degeneration of the nigro-striatal dopamine system. Acta Physiol Scand Suppl (1971) 367:95-122.

42. Nicholas AP. Levodopa-induced hyperactivity in mice treated with 1-methyl4-phenyl-1,2,3,6-tetrahydropyridine. Mov Disord (2007) 22(1):99-104. doi:10. $1002 / \mathrm{mds} .21235$

43. Nutt J, Holford NHG. The response to levodopa in Parkinson's disease: imposing pharmacological law and order. Ann Neurol (1996) 39:561-73. doi:10.1002/ ana.410390504

44. Witt K, Krack P, Deuschl G. Change in artistic expression related to subthalamic stimulation. J Neurol (2006) 253:955-6. doi:10.1007/s00415-006-0127-x

45. Lim SY, O’Sullivan SS, Kotschet K, Gallagher DA, Lacey C, Lawrence AD, et al. Dopamine dysregulation syndrome, impulse control disorders and punding after deep brain stimulation surgery for Parkinson's disease. J Clin Neurosci (2009) 16:1148-52. doi:10.1016/j.jocn.2008.12.010

46. Drago V, Foster PS, Okun MS, Haq I, Sudhyadhom A, Skidmore FM, et al. Artistic creativity and DBS: a case report. J Neurol Sci (2009) 276(1-2):138-42. doi:10.1016/j.jns.2008.09.021

47. Jamison KR. Great wits and madness: more near allied? Br J Psychiatry (2011) 199(5):351-2. doi:10.1192/bjp.bp.111.100586

48. Canesi M, Rusconi ML, Isaias IU, Pezzoli G. Artistic productivity and creative thinking in Parkinson's disease. Eur J Neurol (2012) 19(3):468-72. doi:10.1111/ j.1468-1331.2011.03546.x

49. Schwingenschuh P, Katschnig P, Saurugg R, Ott E, Bhatia KP. Artistic profession: a potential risk factor for dopamine dysregulation syndrome in Parkinson's disease? Mov Disord (2010) 25(4):493-6. doi:10.1002/mds.22936

50. Drago V, Foster PS, Skidmore FM, Heilman KM. Creativity in Parkinson's disease as a function of right versus left hemibody onset. J Neurol Sci (2009) 276 (12):179-83. doi:10.1016/j.jns.2008.09.026

51. Braak H, Del Tredici K, Rub U, de Vos RA, Jansen Steur EN, Braak E. Staging of brain pathology related to sporadic Parkinson's disease. Neurobiol Aging (2003) 24(2):197-211. doi:10.1016/S0197-4580(02)00065-9

52. Dubois B, Pillon B. Cognitive deficits in Parkinson's disease. J Neurol (1997) 244:2-8. doi:10.1007/PL00007725

Conflict of Interest Statement: Eugénie Lhommée: none, Alina Batir: none, JeanLouis Quesada: none, Claire Ardouin: none, Valérie Fraix: none related to the topic of the paper, Eric Seigneuret: none, Stéphan Chabardès: (1) preclinical research grants from Medtronic, not related to the topic of the paper and (2) travel reimbursements, Alim-Louis Benabid: none related to the topic of the paper, Pierre Pollak: none related to the topic of the paper, Paul Krack: (1) grants: GSK, Eutherapie, Novartis, UCB, Boehringer Ingelheim, Orkyn, Aguettant, Teva, Lundbeck, Medtronic, St Jude; (2) advisory boards: Novartis Abbott.

Received: 16 January 2014; accepted: 03 April 2014; published online: 22 April 2014. Citation: Lhommée E, Batir A, Quesada J-L, Ardouin C, Fraix V, Seigneuret E, Chabardès S, Benabid A-L, Pollak $P$ and Krack $P$ (2014) Dopamine and the biology of creativity: lessons from Parkinson's disease. Front. Neurol. 5:55. doi: 10.3389/fneur.2014.00055

This article was submitted to Movement Disorders, a section of the journal Frontiers in Neurology.

Copyright (c) 2014 Lhommée, Batir, Quesada, Ardouin, Fraix, Seigneuret, Chabardès, Benabid, Pollak and Krack. This is an open-access article distributed under the terms of the Creative Commons Attribution License (CC BY). The use, distribution or reproduction in other forums is permitted, provided the original author(s) or licensor are credited and that the original publication in this journal is cited, in accordance with accepted academic practice. No use, distribution or reproduction is permitted which does not comply with these terms. 